Article

\title{
Design, Analysis, and Implementation of an Equalizer Circuit for the Elimination of Voltage Imbalance in a Half-Bridge Boost Converter with Power Factor Correction
}

\author{
Jhon Bayona ${ }^{1, * \mathbb{C}}$, Nancy Gélvez ${ }^{2} \mathbb{D}$ and Helbert Espitia ${ }^{2} \mathbb{D}$ \\ 1 Facultad de Ingeniería, Universidad ECCI, Bogotá 111311, Colombia \\ 2 Facultad de Ingeniería, Universidad Distrital Francisco José de Caldas, Bogotá 11021-110231588, Colombia; \\ nygelvezg@udistrital.edu.co (N.G.); heespitiac@udistrital.edu.co (H.E.) \\ * Correspondence: jbayonan@ecci.edu.co
}

Received: 9 October 2020; Accepted: 14 December 2020; Published: 17 December 2020

\begin{abstract}
For the implementation of a boost converter, the half-bridge topology provides a simpler conversion circuit; however, the voltage imbalance between the capacitors is a critical factor since traditional control methodology decreases the power factor when correcting the imbalance. Consequently, this paper proposes a circuit to correct such imbalance keeping the power factor at the same time. Then, this work carries the analysis, simulation, and implementation of a strategy to reduce voltage imbalance in a half-bridge boost converter with correction of the power factor. The first part offers a description of the equalizer circuit; then, an average model is employed to perform the mathematical analysis. Later, a comparison via simulation is undertaken including other conventional converters in different scenarios. Moreover, an experimental laboratory setup is made; the results show that the equalizer circuit reduces voltage imbalance between the capacitors in a half-bridge booster converter.
\end{abstract}

Keywords: control; half-bridge boost; power electronics; power factor correction; voltage imbalance

\section{Introduction}

In electrical engineering, it is essential to supply power to the wide variety of devices connected to the network, achieved by energy conversion [1]. The devices connected to the network range from domestic use lamps to more complex technologies such as electrical microgrids [2]. The majority of distribution systems operate with alternating current (AC); thus, it is necessary to use power converters that serve as an interface to supply the electronic loads with direct current (DC). This is done through electronic converters; but means an issue for distribution networks since their operation includes harmonic currents, the injection of reactives to the system, and the increase of the total harmonic distortion (THD) [3].

On the other hand, circuits with power factor correction (PFC) are a way to reduce the inconveniences generated by this type of converters. Circuits with PFC allow limiting harmonic currents while decreasing the THD value seen from the network, improving the efficiency of the conversion circuit [4]. With this approach, the waveform of the current supplied presents a sinusoidal behavior with a small phase angle between the current and the voltage, so that from the point of view of the network the load behaves in an almost resistive way [5,6].

According to [7], the high efficiency and power factor of converters are very important since can improve the electrical system's quality. Boost power factor correction via critical conduction mode (CRM) control, and power on control and valley detection technique are applied to converters with 
PFC in electrical appliances, mainly light loads. However, these control schemes have low-efficiency problems due to a sudden increase in the switching frequency with light loads and low power factor associated with the limitation of the power on time.

Different converters with PFC have been implemented evaluating the efficiency under load conditions, such as the cascade buck-boost [8], Cuk converter [9], flyback circuit [10] and boost converter [11]. In this regard, the boost converter has greater efficiency as it can operate in a wide range of loads in continuous and discontinuous mode [12]. Two of the most widely used variations of this converter are half-bridge and full-bridge topology. The half-bridge provides a simpler conversion circuit using fewer switching devices although it requires the use of an additional capacitor [6].

Regarding the applications using converters with power factor correction, in [10] the power-factor-correction converter of a single-stage forward-flyback with quasi-resonant $(\mathrm{QR})$ control is studied. This uses a flyback and direct converters through a common transformer. Only the flyback sub-converter works when the input voltage is less than the reflected output voltage, while both the flyback sub-converter and the direct sub-converter operate to share the output power in the repose region. Other application for Ćuk-type converters can be seen in [13], where a control system for this converter is used to supply power to a fed brushless DC motor. For the design of the controller, moth-flame optimization (MFO) is used to make the settings of a fuzzy logic controller (FLC). The proposed Ćuk converter works in discontinuous conduction mode (DCM) to achieve better power factor.

An attractive control strategy to implement converters with PFC is predictive control; thus, reference [11] presents a digital predictive control strategy for a single-phase boost PFC converter. Considering the structure of the converter circuit, the values of the output voltage and the inductor current of the next switching cycle are predicted in advance. Duty cycle is calculated only through predicted output voltage and steady-state inductor current values, and the optimized duty cycle is predicted during the dynamic process. Meanwhile, in [14] a predictive control algorithm is proposed including the detection of the conduction mode for the power-factor-correction converter. In converters with PFC, the line current is often distorted due to the characteristics of the proportional-integral (PI) current controller. To improve the quality of the current, the optimum duty cycle is determined by estimating the next current state in the continuous conduction mode (CCM) and the discontinuous conduction mode.

Considering digital control applications, authors of [15] describe a digitally controlled power-factor-correction system based on two interleaved drive converters operating with pulse width modulation (PWM). Both converters are controlled independently by an internal regulator loop based on a discrete-time sliding mode (SM) approach that imposes a loss-free resistor (LFR) behavior. The switching surface implements an average current mode driver so that the power factor (PF) is high. Additional work can be seen in [16], where a mixed-signal control scheme is presented for a boost power-factor-correction rectifier. The digital controller modulates the maximum inductor current to produce low distortion at the AC line current in discontinued conduction mode and continuous conduction mode without detecting the average current.

Concerning other applications for the design of a digital control system for power electronic converters, the reference [17] presents an integrated interleaved dual-mode time-sharing inverter (IIDMI) for the grid-tied transformer-less photovoltaic systems. The IIDMI has low total harmonic distortion of the $\mathrm{AC}$ with reduced filtering requirements and reduced current of power devices. The current control, especially transitions between the buck and the boost modes of operation, is made using a fast response dead-beat control (DBC). Likewise, document [18] presents a single-phase transformer-less dual-mode interleaved multilevel inverter (DMIMI) that injects a highly sinusoidal AC to the grid. Dead-beat controllers are developed to calculate the optimal duty cycles directly. The DMIMI offers high efficiency, and fewer components conducting simultaneously in each operation mode. In addition, the work in [19] proposes the application of the dual-mode time-sharing technique in transformer-less photovoltaic inverters. The indirect current control, especially at transition 
modes of operation, is improved using a fast dead-beat control scheme. The system obtains a low leakage current, which is a primary concern with the transformer-less PV inverters. On the other hand, the authors of [20] propose an extendable quadratic bidirectional DC-DC converter with an improved voltage transfer ratio (VTR), capable of redundancy and modularity for electric vehicle applications. The converter has a simple structure with the lowest rating of semiconductors in the family of quadratic bidirectional converters.

Regarding LED (Light-Emitting Diode) applications, the work in [21] presents the design and experimental evaluation of a one-stage AC/DC converter with PFC and a hybrid full-bridge rectifier to supply streetlights. The proposed converter consists of an LLC resonant tank, two boost circuits, and a shared inductor. By incorporating a relay switch on the secondary side of the circuit, the output stage can operate as two different types of rectifier: the first is as a full-bridge rectifier and the second type is as a full-bridge voltage doubling rectifier. In addition, paper [22] presents a single-stage controller with smooth switching and PFC functions for LED street lighting applications. The system integrates a PFC buck-boost converter interleaved with coupled inductors and a half-bridge LLC resonant converter in a single-stage power conversion circuit with reduced voltage across the DC connected capacitor and power switches. The inductors coupled in the interleaved PFC buck-boost converter operate in discontinuous conduction mode to achieve PFC. Additional work can be seen in [23] that presents the implementation of a two-stage light-emitting diode driver. The LED driver circuit design drives a $150 \mathrm{~W}$ LED module. The controller stages are: AC/DC power-factor-correction stage, and DC/DC power converter stage. The PFC stage implementation uses the NCP1608 integrated circuit, which uses the critical conduction mode to ensure unity power factor with a wide range of input voltages.

Regarding other applications made for power-factor-correction converters, reference [24] presents a built-in photovoltaic (PV) power interface circuit with a buck-boost converter and a full-bridge inverter. The circuit consists of five switches, an input inductor, and LC filters. The buck-boost converter operates at a high switching frequency to make the output current a sine wave, while the full-bridge inverter operates at a low switching frequency of $50-60 \mathrm{~Hz}$. A high power factor is achieved in the output stage without an additional current driver due to the input inductor current operating in a discontinuous conduction mode.

The central aspect to considerer in this paper is that for implementing a boost converter, the half-bridge topology provides a simpler conversion circuit by using fewer switching devices; however, the voltage imbalance between the capacitors is a critical study factor. Previous research [25] aims at finding alternatives to eliminate the cause of imbalance and outlines for designing a power circuit using a fixed band hysteresis current control (HCC) technique. In [26], it is proposed to add a DC bias to each phase's current source to solve the voltage imbalance problem. Elimination strategies are developed by carefully analyzing all possible paths of DC bias currents and their effect on voltage imbalance. Later in [27], these same authors study the adverse effects of the imbalance elimination control circuit on the input power factor. Finally, a related work to consider is presented in [28], which analyzes a four-switch voltage doubler boost rectifier. The authors propose a control scheme to eliminate output voltage imbalance when the load is imbalanced between the two output DC rails. To limit the output voltage imbalance, the controller employs a comparator with hysteresis. Unipolar pulse width modulation switching patterns are used to reduce the discharge rate of the output capacitor for low voltages. Figure 1 shows the traditional control methodology to correct the imbalance; however, injecting a direct component to $i_{L_{R E F}}$ or generating a phase difference between $i_{g}$ and $v_{g}$ decreases the PF [6]. Therefore, the possibility is open for the development of alternatives to correct the imbalance. 


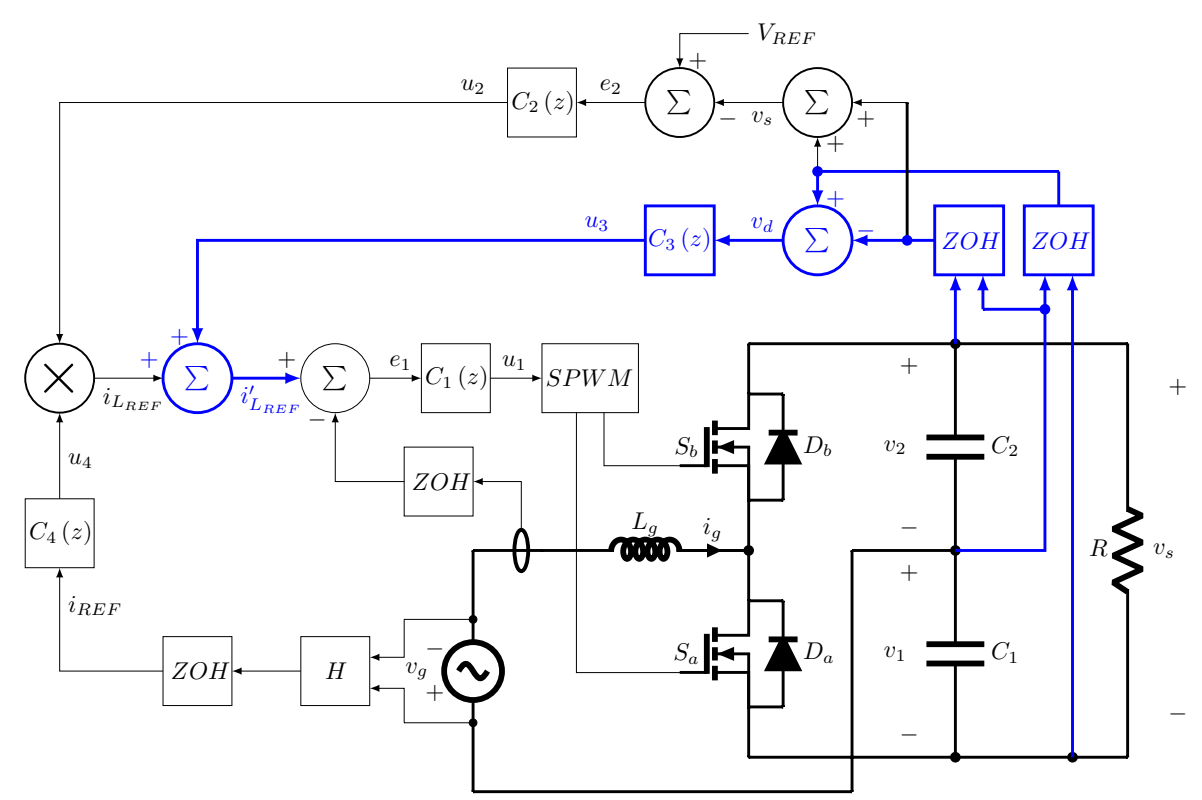

Figure 1. Control diagram with differential voltage loop for a converter with power factor correction in half-bridge configuration.

Table 1 and Figure 2 describe the related works showing the relevance of low power factor converters, emphasizing the half-bridge boost converter. The main issue here is the voltage imbalance; moreover, some applications and control strategies are also displayed.

Table 1. Description of the related works.

\begin{tabular}{clc}
\hline Topic & Description & References \\
\hline Power Factor & $\begin{array}{l}\text { General aspects about power quality, power factor and } \\
\text { harmonic distortion in electrical systems }\end{array}$ & {$[1-7]$} \\
\hline Converters PFC & $\begin{array}{l}\text { Provision of a general description of PFC converters, cascade } \\
\text { buck-boost, Ćuk converter, flyback circuit, and boost converter }\end{array}$ & {$[6,8-10,10-12]$} \\
\hline Fuzzy logic control & $\begin{array}{l}\text { PFC converter control using fuzzy logic in the application to } \\
\text { supply power to a fed brushless DC motor }\end{array}$ & {$[13]$} \\
\hline Predictive control & $\begin{array}{l}\text { Predictive control application for PFC converters, the system } \\
\text { calculates the future value of the duty cycle }\end{array}$ & {$[11,14]$} \\
\hline Digital Controller & $\begin{array}{l}\text { It shows a brief review of different applications of converters } \\
\text { using digital controllers }\end{array}$ & {$[15-20]$} \\
\hline LED applications & $\begin{array}{l}\text { Application of PFC converters for LED lighting using } \\
\text { full-bridge and half-bridge rectifiers }\end{array}$ & {$[21-23]$} \\
\hline Photovoltaic applications & $\begin{array}{l}\text { Description of the application of PFC converters in } \\
\text { photovoltaic systems }\end{array}$ & {$[17,24]$} \\
\hline Voltage Imbalance & $\begin{array}{l}\text { Describe main works related to the imbalance in half-bridge } \\
\text { rectifiers. This issue is addressed in this work }\end{array}$ & {$[25-28]$} \\
\hline
\end{tabular}




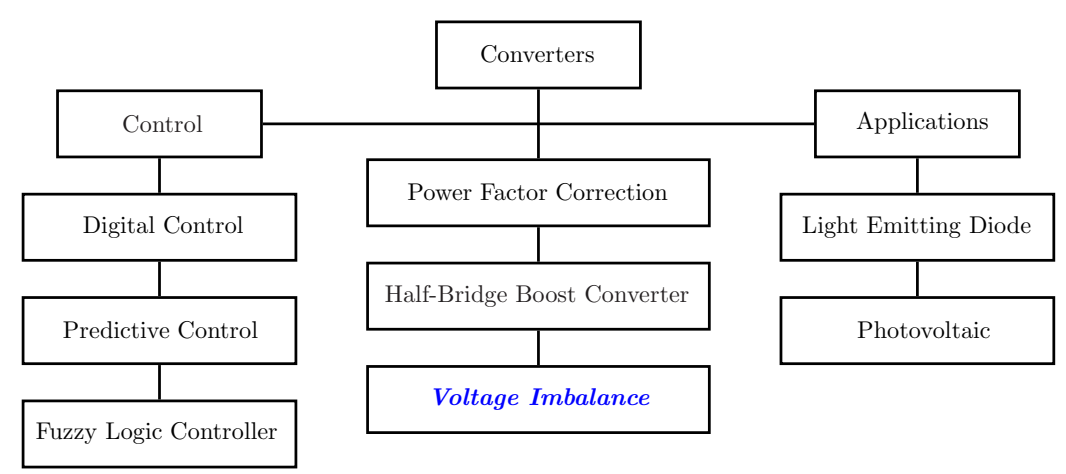

Figure 2. Graphic description of the related works.

This article focuses on showing that the proposed topology allows the reduction of the capacitor imbalance in a half-bridge boost converter. For this, mathematical analysis and experimental tests are carried out. In classical topologies, when correcting the imbalance, the power factor is sacrificed as shown in [25]. Thus, it is presented a switched DC/DC converter circuit (equalizer) operating in discontinuous conduction mode that solves the voltage imbalance problem in the half-bridge boost converter. The proposed equalizer circuit is added to the voltage doubler boost rectifier. It is composed of two transistors, in this case, MOSFETs $S_{1}, S_{2}$ and the respective diodes $D_{1}, D_{2}$, as well as an inductance $L$. As a result, a voltage doubler boost rectifier with equalizer is originated, which is shown in Figure 3. In addition, $h$ is the duty cycle associated with the switches $S_{a}$ and $S_{b}$ of the doubler-rectifier-elevator, and $1-h$ correspond to the complement.

The document is organized as follows: Section 2 qualitatively describes the equalizer circuit operation, its average circuit model is given in Section 3. Section 4 presents a detailed analysis of the equalizer's voltage elimination imbalance using its average circuit model. Aiming to eliminate the voltage imbalance, Section 5 proposes a hysteretic band control scheme to govern (control) the equalizer. A comparison whit other classic converters via simulation appears in Section 6, later in Section 7 a prototype of the voltage doubler boost rectifier with the proposed equalizer circuit is built to test it and validate the theoretical analysis; finally, the conclusions are given.

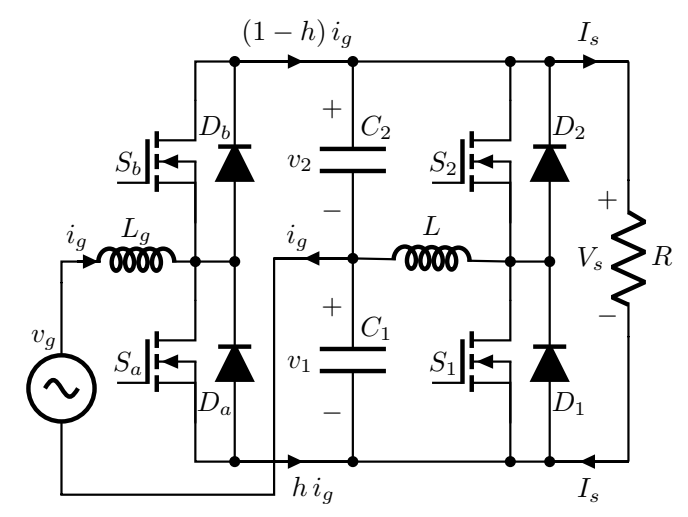

Figure 3. Voltage doubler boost rectifier with equalizer.

\section{Description of the Proposed Equalizer Circuit}

As previously mentioned, the imbalance of voltages in the capacitors in a half-bridge boost converter is a critical factor, which is why this document analyzes, designs and implements a strategy called equalizer circuit to eliminate the voltage imbalance on the capacitors.

To explain the operation of the proposed equalizer circuit operating in DCM, it is considered that the output capacitors $C_{1}$ and $C_{2}$ are sufficiently large, so that the voltage ripples produced by switching frequency and line frequency can be neglected; on the other hand, all components of the equalizer circuit are ideal. According to the comparison between the voltages of the capacitors, two 
modes arise in the operation of the equalizer circuit that affect the state of charge and discharge of both capacitors, as described below:

\subsection{Analysis for the Case $V_{1}>V_{2}$}

In this mode, the transistor $S_{1}$ and the diode $D_{2}$ operate, as shown in Figure 4; likewise, the waveforms of the current $i^{\prime}$ and the voltage $v^{\prime}$ of the inductance for this mode are shown in Figure 5. The inductance current is equal to zero at the beginning of each switching period $T_{s}$, during the first interval $d_{1} T_{s}$, simultaneously the transistor $S_{1}$ is turned on and the diode $D_{2}$ turns off; the voltage of the inductance is equal to $V_{1}$; hence, the current of the inductance increases with a slope equal to $\frac{V_{1}}{L}$, at the end of this first interval, the inductance current reaches its maximum value given by:

$$
I_{m}=\frac{V_{1}}{L} d_{1} T_{s}
$$

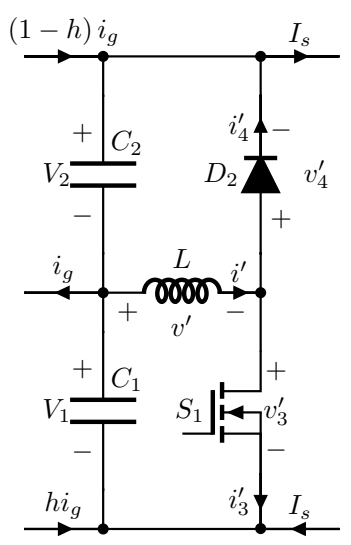

Figure 4. Equalizer circuit for the case $V_{1}>V_{2}$.

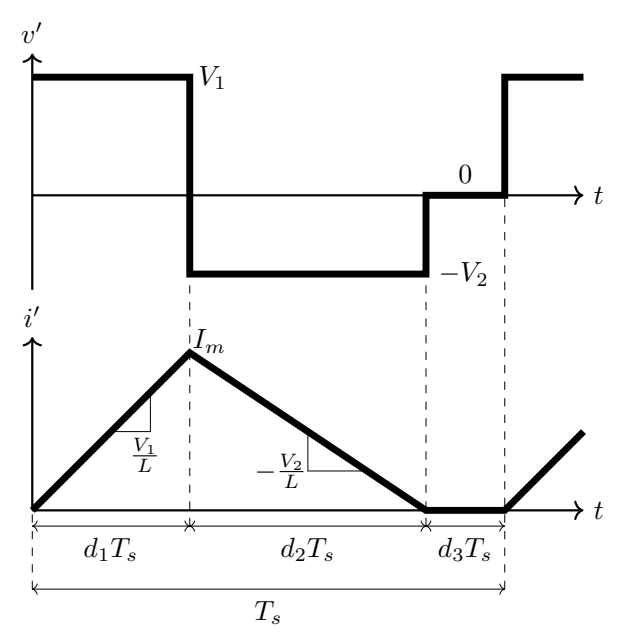

Figure 5. Waveforms of $v^{\prime}$ and $i^{\prime}$ associated with the equalizer circuit for the case $V_{1}>V_{2}$.

Therefore, the maximum current value $I_{m}$ is directly proportional to the voltage of the capacitor $C_{1}$, as well as to the duration of the first interval, therefore, the inductance absorbs energy from the capacitor $C_{1}$, which is proportional to the square of $I_{m}$ and is given by:

$$
W=\frac{1}{2} L I_{m}^{2}
$$

During the second interval $d_{2} T_{s}$ the transistor $S_{1}$ turns off. Meanwhile, the diode $D_{2}$ turns on, the inductance voltage is equal to $-V_{2}$, then, the inductance current decreases with a slope equal 
to $-\frac{V_{2}}{L}$, at the end of this second interval the diode $D_{2}$ is polarized in inverse and the energy that the inductance absorbed during the first interval is transferred to the capacitor $C_{2}$. The inductance current and voltage are kept at zero during the third interval $d_{3} T_{s}$. Consequently, the equalizer circuit discharges the capacitor $C_{1}$ during the first interval and charges the capacitor $C_{2}$ during the second interval in this mode.

\subsection{Analysis for the Case $V_{2}>V_{1}$}

In Figure 6, waveforms of the current $i^{\prime}$ and the voltage $v^{\prime}$ of the inductance are equal to the previous mode. Nevertheless, the direction of the current and the voltage polarity are reversed, as illustrated in Figure 7, where is seen that the transistor $S_{2}$ and the diode $D_{1}$ now operate. Similar to the previous mode, the inductance current is equal to zero at the beginning of each switching period $T_{s}$, during the first interval $d_{1} T_{s}$, the transistor $S_{2}$ is turned on, simultaneously, diode $D_{1}$ turns off, the inductance voltage equals $V_{2}$; therefore, the inductance current increases with a slope equal to $\frac{V_{2}}{L}$, at the end of this first interval, the inductance current reaches its maximum value given by:

$$
I_{m}=\frac{V_{2}}{L} d_{1} T_{s}
$$

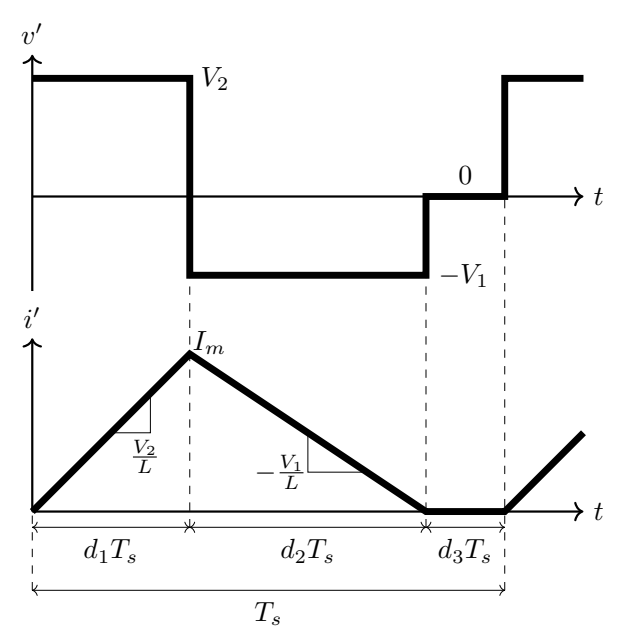

Figure 6. Waveforms of $v^{\prime}$ and $i^{\prime}$ associated with the equalizer circuit for the case $V_{2}>V_{1}$.

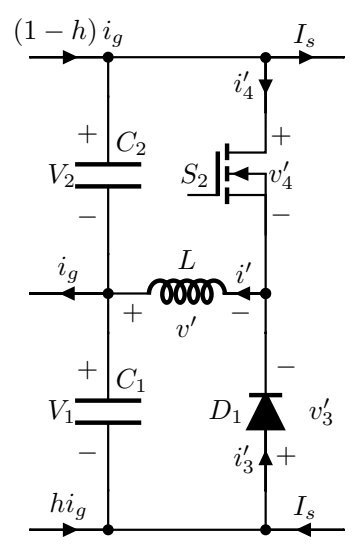

Figure 7. Equalizer circuit for the case $V_{2}>V_{1}$.

Therefore, the maximum value of current $I_{m}$ is directly proportional to the voltage of the capacitor $C_{2}$ and the duration of the first interval; then, the inductance absorbs energy from the capacitor $C_{2}$, which is proportional to the square of $I_{m}$ and is given by (2). During the second interval $d_{2} T_{s}$, the transistor $S_{2}$ turns off. Meanwhile, diode $D_{1}$ turns on, and inductance voltage is equal to $-V_{1}$, 
which is why the inductance current decreases with a slope equal to $-\frac{V_{1}}{L}$; at the end of this second interval, diode $D_{1}$ is reverse biased, and the energy absorbed by the inductance during the first interval is transferred to the capacitor $C_{1}$. The inductance current and voltage are kept at zero during the third interval $d_{3} T_{s}$. As a result, the equalizer circuit discharges the capacitor $C_{2}$ during the first interval and charges the capacitor $C_{1}$ during the second interval in this mode.

From the above, when $V_{1}>V_{2}$, the equalizer absorbs energy from $C_{1}$, which is delivered to $C_{2}$, then, $V_{1}$ decreases, at the same time $V_{2}$ increases; likewise, when $V_{2}>V_{1}$, the equalizer absorbs energy from $C_{2}$ that is delivered to $C_{1}$; hence $V_{2}$ decreases while $V_{1}$ increases; to conclude, the equalizer circuit eliminates the voltage imbalance that occurs in the capacitors. In Section 4 , a more detailed analysis is made using the average circuit model of the equalizer circuit.

\section{Average Circuit Model}

The average circuit model of the equalizer in each operating mode is obtained by following the average switch-modeling technique [29], which generates an equivalent circuit that models the average of the waveforms at the terminals of the switch network. In relation to the equalizer when $V_{1}>V_{2}$, Figure 4 shows the equivalent circuit of the transistor $S_{1}$ and diode $D_{2}$, which is obtained by averaging the respective waveforms of the inductance current, capacitor voltage, and duty cycle.

The average voltage associated with $S_{1}$ is $v_{3}$, this is found by averaging the waveform $v_{3}^{\prime}$ shown in Figure 8.

$$
v_{3}=d_{2}\left(V_{1}+V_{2}\right)+d_{3} V_{1},
$$

from any of the waveforms, it follows that $d_{3}$ can be expressed as:

$$
d_{3}=1-d_{1}-d_{2}
$$

replacing (5) in (4) is obtained:

$$
v_{3}=d_{2} V_{2}+\left(1-d_{1}\right) V_{1}
$$

likewise, $i_{3}$ is the average current of $S_{1}$ and it is found by averaging the waveform $i_{3}^{\prime}$ shown in Figure 8 .

$$
i_{3}=\frac{1}{2} d_{1} I_{m},
$$

substituting (1) in (7), yield:

$$
i_{3}=\frac{1}{2} \frac{d_{1}^{2} V_{1} T_{s}}{L}
$$

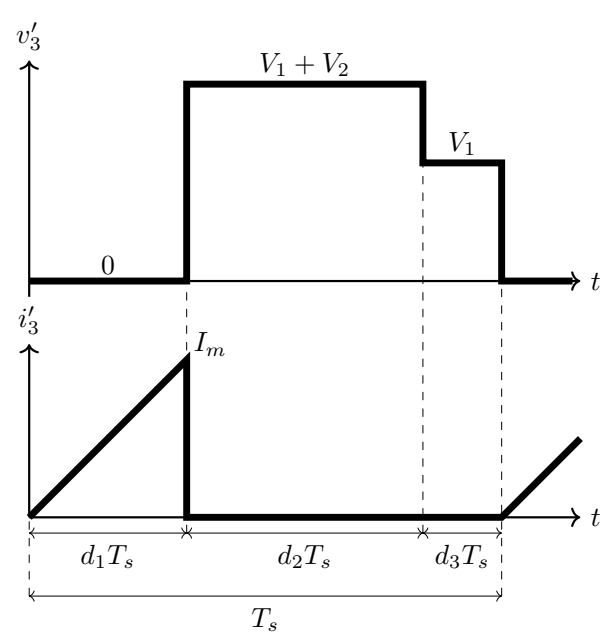

Figure 8. Voltage and current waveforms associated with $S_{1}$ for the equalizer circuit when $V_{1}>V_{2}$. 
The average voltage of $D_{2}$ is $v_{4}$, this voltage is found by averaging the waveform $v_{4}^{\prime}$ shown in Figure 9.

$$
v_{4}=d_{1}\left(V_{1}+V_{2}\right)+d_{3} V_{2}
$$

substituting (5) in (9) produces:

$$
v_{4}=d_{1} V_{1}+\left(1-d_{2}\right) V_{2}
$$

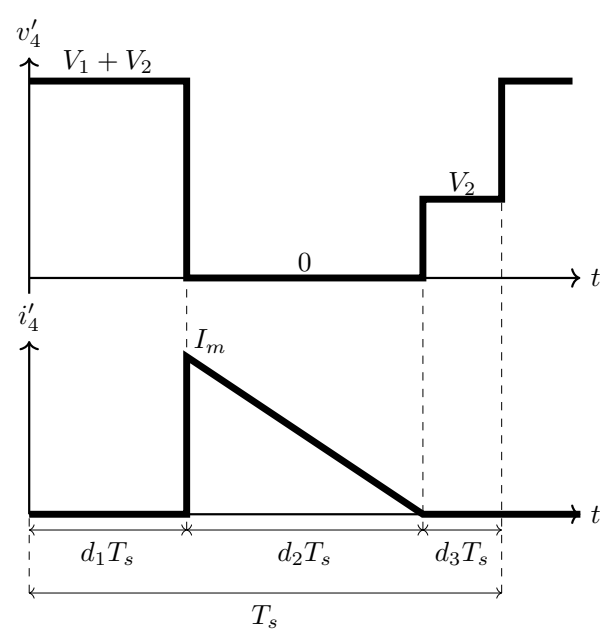

Figure 9. Voltage and current waveforms associated with $D_{2}$ for the equalizer circuit when $V_{1}>V_{2}$.

Similarly, $i_{4}$ is the average current of $D_{2}$ and it is found by averaging the waveform $i_{4}^{\prime}$ shown in Figure 9.

$$
i_{4}=\frac{1}{2} d_{2} I_{m}
$$

substituting Equation (1) in (11), yield:

$$
i_{4}=\frac{1}{2} \frac{d_{1} d_{2} V_{1} T_{s}}{L}
$$

On the other hand, Figure 5 shows no change in current $i^{\prime}$ over a commutation period, having as a result:

$$
\frac{L}{T_{S}}\left[i^{\prime}\left(t+T_{S}\right)-i^{\prime}(t)\right]=\frac{1}{T_{S}} \int_{t}^{t+T_{S}} v^{\prime} d \tau=0
$$

and since:

$$
v=\frac{1}{T_{s}} \int_{t}^{t+T_{s}} v^{\prime} d \tau
$$

the average voltage of the inductance $v$ is equal to zero and the average of the waveform $v^{\prime}$ shown in Figure 5 , is given by:

$$
v=d_{1} V_{1}-d_{2} V_{2}=0
$$

solving $d_{2}$ then:

$$
d_{2}=d_{1} \frac{V_{1}}{V_{2}}
$$

therefore, the average of each of the waveforms is obtained, at the terminals of $S_{1}$ and $D_{2}$, substituting (16) in (6), (8), (10), and (12), is obtained:

$$
\begin{aligned}
& v_{3}=V_{1} \\
& v_{4}=V_{2}
\end{aligned}
$$




$$
\begin{aligned}
i_{3} & =\frac{1}{2} \frac{d^{2} v_{3} T_{s}}{L} \\
i_{4} & =\frac{1}{2} \frac{d^{2} v_{3}^{2} T_{s}}{L v_{4}}
\end{aligned}
$$

where $d$ is the duty cycle equal to $d_{1}$; in conclusion, Equations (17)-(20) are simple expressions that represent the average of the waveforms of the transistor $S_{1}$ and diode $D_{2}$ of the equalizer circuit in $\mathrm{DCM}$, when $V_{1}>V_{2}$.

To find a circuit that models the $S_{1}$ and $D_{2}$ waveforms, it is considered that $S_{1}$ absorbs and $D_{2}$ delivers apparent average power. According to Figure $4, S_{2}$ absorbs apparent power, since its current enters through the positive value of its voltage, at the same time, $D_{2}$ delivers apparent power, since its current leaves through the positive value of its voltage; in addition, the apparent average power of $S_{1}$ and $D_{2}$ are equal and expressed as:

$$
v_{3} i_{3}=v_{4} i_{4}=\frac{1}{2} \frac{d^{2} V_{1}^{2} T_{s}}{L}
$$

Also, the apparent average power of $S_{1}$ and $D_{2}$ is deduced considering the energy stored by the inductance and expressing its maximum current reached $I_{m}$, during the first interval of time $d T_{s}$ in terms of the voltage $V_{1}$; therefore, replacing (1) in (2) is obtained:

$$
W=\frac{1}{2} \frac{\left(d T_{s} V_{1}\right)^{2}}{L},
$$

dividing both sides of (22) by the commutation period $T_{S}$, it is obtained the power absorbed by the inductance during the first time interval, equal to the expression given in (21). As a result, it can be stated that during the first time interval, the power is transferred from the capacitor $C_{1}$ to the inductance $L$ through the terminals of the transistor $S_{1}$. During the second time interval the inductance $L$ releases all the energy stored to the capacitor $C_{2}$, through the terminals of diode $D_{2}$; then, the average power consumed by the transistor and the diode equals zero, i.e., the transistor $S_{1}$ behaves like a power source that absorbs $P_{1}$. Simultaneously, the diode $D_{2}$ behaves like a power source that supplies $P_{2}$. The power $P_{2}$ is dependent on the power $P_{1}$, since the voltage and current of the $S_{1}$ terminals are independent of the voltage and current from the $D_{2}$ terminals.

Therefore, the equalizer average model when $V_{1}>V_{2}$ is represented by two power sources that substitute transistor $S_{1}$ and diode $D_{2}$, as shown in Figure 10. Source $P_{1}$ absorbs power that is later transferred to source $P_{2}$, whereby source $P_{1}$ absorbs power from capacitor $C_{1}$ that flows to the source $P_{2}$ and then to capacitor $C_{2}$. Also, in Figure 10 is seen the replacement of the inductance by a short circuit considering average voltage equal to zero; likewise, the current $i$ that flows through this short circuit is the average current of inductance $i^{\prime}$.

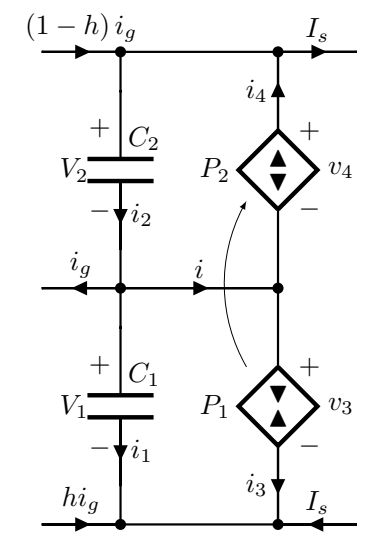

Figure 10. Average circuit model of the equalizer when $V_{1}>V_{2}$. 
The equalizer circuit when $V_{2}>V_{1}$ is illustrated in Figure 7 , this represents the equivalent circuit composed by the transistor $S_{2}$ and diode $D_{1}$. By averaging the waveforms in terms of the equalizer input and state variables is obtained:

$$
\begin{aligned}
i_{3} & =\frac{1}{2} \frac{d^{2} v_{4}^{2} T_{s}}{L v_{3}} \\
i_{4} & =\frac{1}{2} \frac{d^{2} v_{4} T_{s}}{L}
\end{aligned}
$$

The average circuit model of the equalizer when $V_{2}>V_{1}$ consists of two power sources that replace the transistor $S_{2}$ and diode $D_{1}$ as shown in Figure 11. The source $P_{2}$ absorbs power that is transferred to the source $P_{1}$; hence, the source $P_{2}$ absorbs power from the capacitor $C_{2}$ that flows to $P_{1}$, and then to $C_{1}$. The inductance is replaced by a short circuit in the same way than in the average equalizer circuit when $V_{1}>V_{2}$.

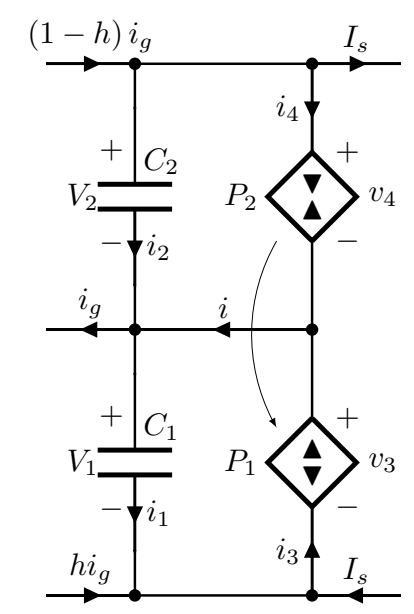

Figure 11. Average circuit model of the equalizer when $V_{2}>V_{1}$.

\section{Voltage Imbalance Analysis}

To start the analysis in the voltage doubler boost rectifier, it is considered that the voltage variations in both capacitors are produced by the line frequency. The line voltage varies in a sinusoidal way and to obtain a unitary PF; also, the line current is sinusoidal, having:

$$
\begin{gathered}
v_{g}=V_{p} \sin (\theta) \\
i_{g}=I_{p} \sin (\theta)
\end{gathered}
$$

On the other hand, the average circuit models of the proposed equalizer obtained in Section 3 are used to calculate the steady-state voltage imbalance in the voltage doubler boost rectifier capacitors, in each mode of operation of the equalizer proposed.

\subsection{Analysis for the Case $V_{1}>V_{2}$}

In this mode, the average equalizer circuit is connected to the voltage doubling step-up rectifier capacitors, as shown in Figure 10, from which the average currents $i_{1}$ and $i_{2}$ are expressed as:

$$
\begin{gathered}
i_{1}=-h i_{g}-I_{s}-i_{3} \\
i_{2}=(1-h) i_{g}-I_{s}+i_{4}
\end{gathered}
$$


By substituting (17) and (18) in (19) and (20), the average currents $i_{3}$ and $i_{4}$ are obtained in terms of the average voltages of the capacitors $V_{1}$ and $V_{2}$ having:

$$
\begin{aligned}
& i_{3}=\frac{d^{2} V_{1} T_{s}}{2 L} \\
& i_{4}=\frac{d^{2} V_{1}^{2} T_{s}}{2 L V_{2}}
\end{aligned}
$$

The average voltage of the inductance $L_{g}$, in the voltage doubler boost rectifier $[5,30]$ is given by:

$$
L_{g} \frac{d i_{g}}{d t}=v_{g}+V_{1}-(1-h) V_{s},
$$

where $V_{s}=V_{1}+V_{2}$, and replacing (25) and (26) in (31) yield:

$$
\omega L_{g} I_{p} \cos (\theta)=V_{p} \sin (\theta)+V_{1}-(1-h) V_{s},
$$

solving $h$ from (32) is obtained:

$$
h=\frac{\omega L_{g} I_{p}}{V_{s}} \cos (\theta)-\frac{V_{p}}{V_{s}} \sin (\theta)-\frac{V_{1}}{V_{s}}+1,
$$

comparing magnitude for sine and cosine signals $\frac{V_{p}}{V_{s}} \gg \frac{\omega L_{g} I_{p}}{V_{s}}$, it is established that $V_{p} \gg \omega L_{g} I_{p}$, then Equation (33) can be approximated to:

$$
h=-\frac{V_{p}}{V_{s}} \sin (\theta)-\frac{V_{1}}{V_{s}}+1,
$$

replacing (26), (29), (30), and (34) in (27), and (28), is obtained:

$$
\begin{aligned}
& i_{1}=\frac{V_{p} I_{p}}{V_{s}} \sin ^{2}(\theta)-\frac{V_{2} I_{p}}{V_{s}} \sin (\theta)-I_{s}-\frac{d^{2} T_{s} V_{1}}{2 L} \\
& i_{2}=\frac{V_{p} I_{p}}{V_{s}} \sin ^{2}(\theta)+\frac{V_{1} I_{p}}{V_{s}} \sin (\theta)-I_{s}+\frac{d^{2} T_{s} V_{1}^{2}}{2 L V_{2}}
\end{aligned}
$$

Considering that the duty cycle $d$ is constant, then, the variations of the voltages in the capacitors $V_{1}$ and $V_{2}$ over a switching period are given by:

$$
\begin{aligned}
& \delta V_{1}=\frac{1}{\omega C_{1}} \int_{0}^{2 \pi} i_{1} d \theta=\frac{\pi}{\omega C_{1}}\left(\frac{V_{p} I_{p}}{V_{s}}-2 I_{s}-\frac{d^{2} T_{s} V_{1}}{L}\right) \\
& \delta V_{2}=\frac{1}{\omega C_{2}} \int_{0}^{2 \pi} i_{2} d \theta=\frac{\pi}{\omega C_{2}}\left(\frac{V_{p} I_{p}}{V_{s}}-2 I_{s}+\frac{d^{2} T_{s} V_{1}^{2}}{L V_{2}}\right)
\end{aligned}
$$

It is assumed that $C_{1}$ and $C_{2}$ are equal to $C$; hence, the variation of the voltage difference over a switching period, with the proposed equalizer when $V_{1}>V_{2}$ is given by:

$$
\delta V_{2}-\delta V_{1}=\frac{\pi d^{2} T_{s}}{\omega L C}\left(\frac{V_{1}^{2}}{V_{2}}+V_{1}\right)
$$

\subsection{Analysis for the Case $V_{2}>V_{1}$}

According to Figure 11, the average currents $i_{1}$ and $i_{2}$ of the average equalizer circuit are given by:

$$
i_{1}=-h i_{g}-I_{s}+i_{3}
$$




$$
i_{2}=(1-h) i_{g}-I_{S}-i_{4}
$$

On the other hand, by replacing (17) and (18) in (23) and (24), respectively, the average currents $i_{3}$ and $i_{4}$ are obtained in terms of the average voltages of the capacitors $V_{1}$ and $V_{2}$ being:

$$
\begin{aligned}
& i_{3}=\frac{d^{2} V_{2}^{2} T_{s}}{2 L V_{1}} \\
& i_{4}=\frac{d^{2} V_{2} T_{s}}{2 L}
\end{aligned}
$$

Substituting (26), (34), (42), and (43) in (40) and (41) yield:

$$
\begin{aligned}
& i_{1}=\frac{V_{p} I_{p}}{V_{s}} \sin ^{2}(\theta)-\frac{V_{2} I_{p}}{V_{s}} \sin (\theta)-I_{s}+\frac{d^{2} T_{s} V_{2}^{2}}{2 L V_{1}} \\
& i_{2}=\frac{V_{p} I_{p}}{V_{s}} \sin ^{2}(\theta)+\frac{V_{1} I_{p}}{V_{s}} \sin (\theta)-I_{s}-\frac{d^{2} T_{s} V_{2}}{2 L}
\end{aligned}
$$

Since the duty cycle $d$ is constant, the variations of the voltages in the capacitors $V_{1}$ and $V_{2}$ over a switching period are expressed as:

$$
\begin{aligned}
& \delta V_{1}=\frac{1}{\omega C_{1}} \int_{0}^{2 \pi} i_{1} d \theta=\frac{\pi}{\omega C_{1}}\left(\frac{V_{p} I_{p}}{V_{s}}-2 I_{s}+\frac{d^{2} T_{s} V_{2}^{2}}{L V_{1}}\right) \\
& \delta V_{2}=\frac{1}{\omega C_{2}} \int_{0}^{2 \pi} i_{2} d \theta=\frac{\pi}{\omega C_{2}}\left(\frac{V_{p} I_{p}}{V_{s}}-2 I_{s}-\frac{d^{2} T_{s} V_{2}}{L}\right)
\end{aligned}
$$

Since $C_{1}$ and $C_{2}$ are equal to $C$, the variation of the voltage differs over a switching period, with the proposed equalizer when $V_{2}>V_{1}$ is expressed as:

$$
\delta V_{1}-\delta V_{2}=\frac{\pi d^{2} T_{s}}{\omega L C}\left(\frac{V_{2}^{2}}{V_{1}}+V_{2}\right)
$$

From this analysis, it is stated that the variations in the difference voltage expressed in (39) and (48) are always positive; as a result, the voltage imbalance is eliminated in both modes of operation, using the proposed equalizer circuit. This elimination is achieved regardless of the load conditions in the voltage doubler boost rectifier.

\section{Control Scheme}

The proposed control scheme that governs the equalizer circuit in DCM, is shown in Figure 12, this scheme is a circuit that allows the passage of a carrier signal $v_{x}$ to the transistor $S_{1}$ or $S_{2}$.

When $V_{1}>V_{2}$, the carrier pass to $S_{1}$ is enabled; simultaneously, $S_{2}$ is set to zero and then the equalizer circuit operates in mode $V_{1}>V_{2}$, absorbing energy from $C_{1}$ which flows towards $C_{2}$, so that $V_{1}$ decreases and $V_{2}$ increases. On the other hand, if $V_{2}>V_{1}$, the carrier pass to $S_{2}$ is enabled, at the same time, $S_{1}$ is set to zero; therefore, the equalizer circuit operates in the mode $V_{2}>V_{1}$, in which it absorbs energy from $C_{2}$ which then flows to $C_{1}$; as a result, $V_{2}$ decreases and $V_{1}$ increases. The carrier signal $v_{x}$ establishes the duty cycle $d$ and the switching period $T_{s}$ of the equalizer, in addition, the duty cycle $d$ is constant and its value is chosen to ensure the operation on DCM of the equalizer; therefore, the equalizer in mode $V_{1}>V_{2}$ operates on DCM when:

$$
d<\frac{V_{2}}{V_{1}+V_{2}}
$$


on the other hand, the equalizer in the mode $V_{2}>V_{1}$ operates in DCM if:

$$
d<\frac{V_{1}}{V_{1}+V_{2}}
$$

The conclusion from (49) and (50) is that the duty cycle $d$ must be less than 0.5 to ensure the equalizer operation in DCM for both modes; also, the duty cycle $d$ determines the energy absorbed by the inductance. On the other hand, the hysteresis band of the comparator must be selected carefully, a wide band produces a high voltage imbalance; likewise, as there is ripple in the voltages $V_{1}$ and $V_{2}$, a narrow band can cause malfunctions in the proposed control scheme.

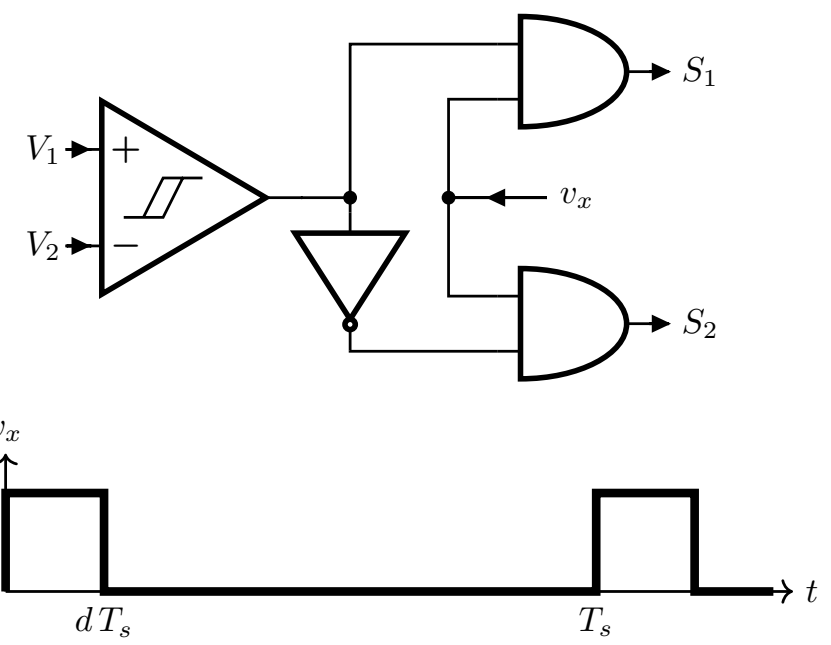

Figure 12. Control scheme of the equalizer circuit.

The hysteresis band was selected considering the variation that can be held in the voltage capacitors. In an experimental way using simulation, different values, displayed in Table 2, are obtained to determine this band, where $B H$ is the hysteresis band and $V_{d}=V_{1}-V_{2}$ is the difference voltage value between the capacitors. In Table 2, as $B H$ increases, $V_{d}$ also increases; therefore, it is appropriate to have a small value of $B H$; however, the operation of the elements is not ideal implying practical limitations. Therefore, using the values of Table 2 in the real circuit, the smallest useful value of $B H$ is $3 \mathrm{~V}$, because for low values of $B H$ undesired oscillations that do not appear in simulation are present in the real circuit.

Table 2. Hysteresis band values obtained in simulation.

\begin{tabular}{cc}
\hline $\boldsymbol{B H}(\mathrm{V})$ & $\boldsymbol{V}_{\boldsymbol{d}}(\mathrm{V})$ \\
\hline 0.25 & \pm 1.58 \\
\hline 0.5 & \pm 1.98 \\
\hline 1 & \pm 1.71 \\
\hline 2 & \pm 2.47 \\
\hline 3 & \pm 3 \\
\hline 4 & \pm 3.5 \\
\hline
\end{tabular}

\section{Simulation Results}

This section presents the comparison of the proposed circuit versus other classic configurations via simulation. The first part of the results show that the proposed circuit does not affect drastically the power factor, the harmonic distortion and the power efficiency. Later it is observed the effect that the variation of the capacitors has on the PF for the simulated circuits. The converters considered are: 
- $\quad$ CV1: Converter proposed with equalizer circuit. The simulation scheme is show in Figure 13.

- CV2: Classic PFC converter using half-bridge boost topology developed in [25]. The diagram of the simulation is show in Figure 14.

- CV3: Half-bridge PFC Boost converter with digital PID controller and pre-compensation loop developed in [6]. The scheme of the simulation is presented in Figure 15.

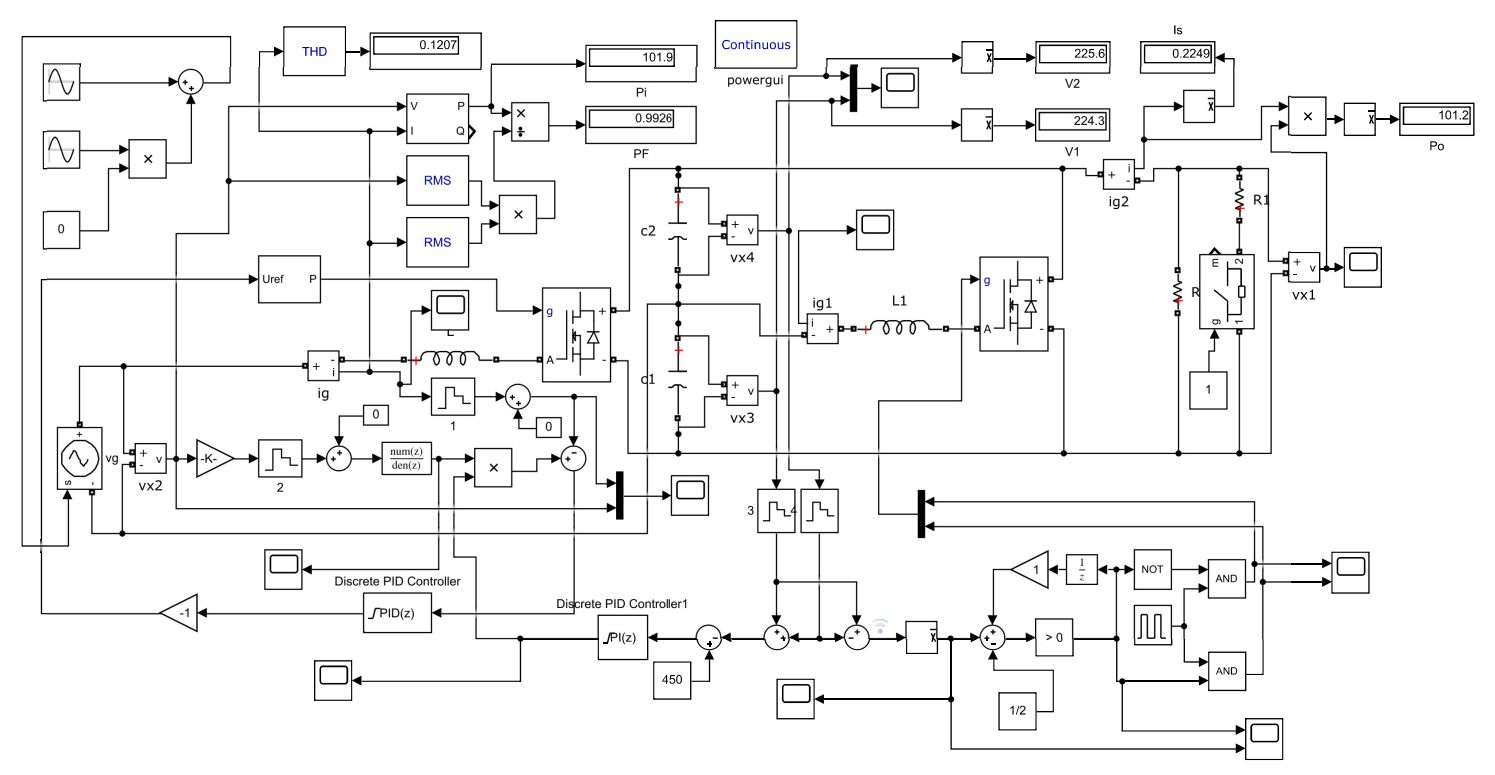

Figure 13. Simulation scheme for CV1.

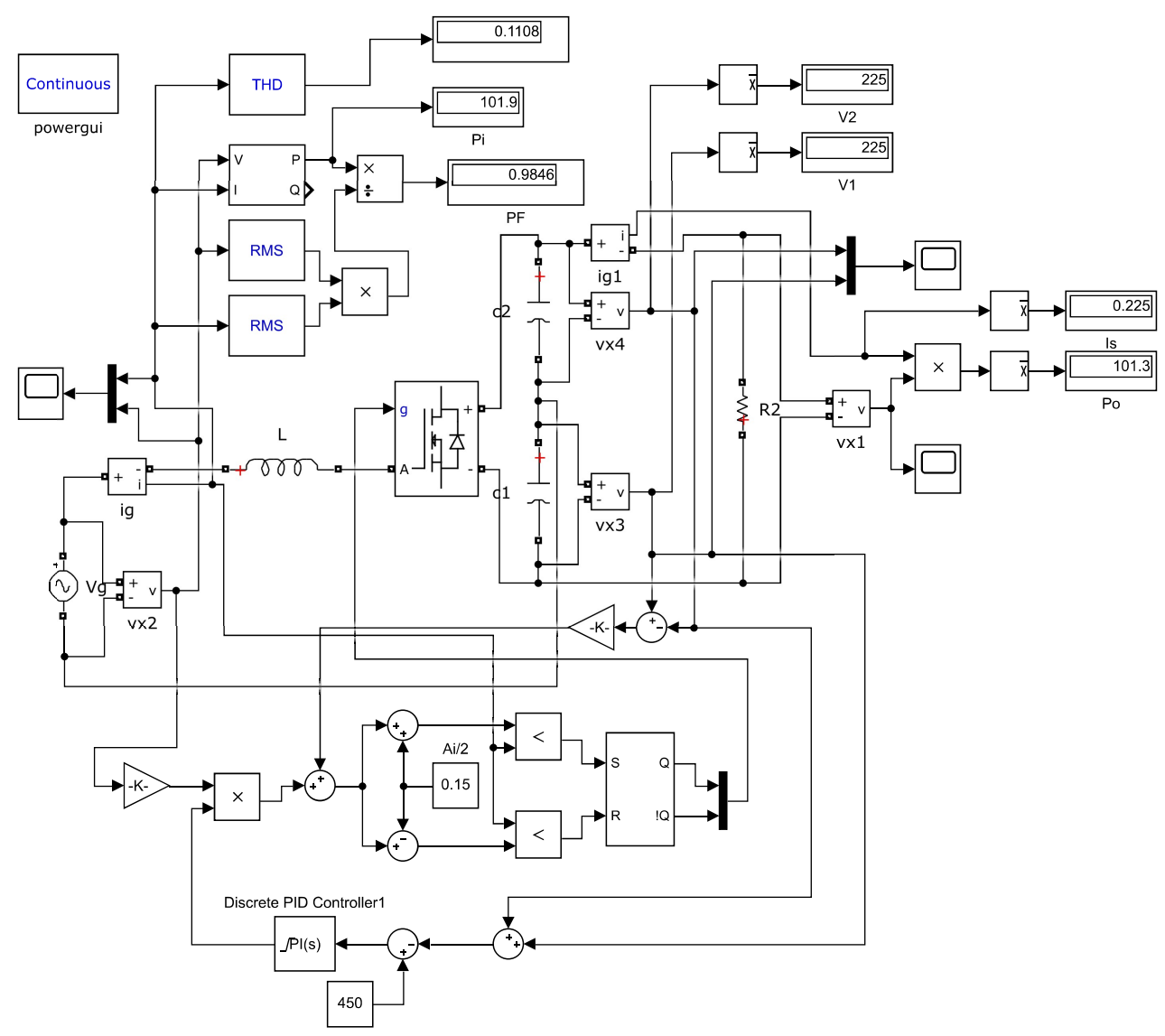

Figure 14. Simulation diagram for CV2. 


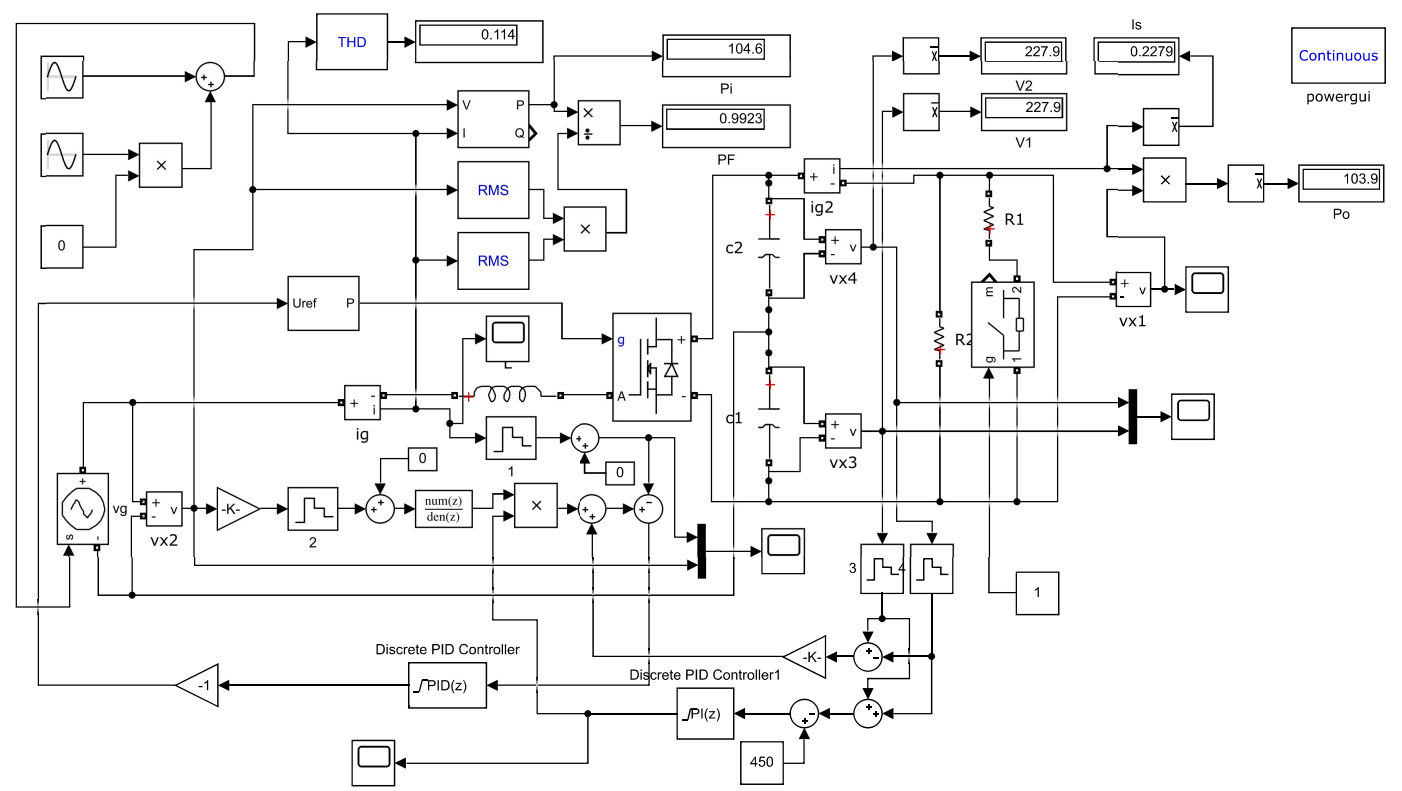

Figure 15. Simulation scheme for CV3.

For comparison, different load current $I_{S}$ values are considered $0.225 \mathrm{~A}, 0.168 \mathrm{~A}$ and $0.112 \mathrm{~A}$; thus Table 3 shows the root mean square (RMS) voltage of $V_{1}$ and $V_{2}$ which corresponds to voltages in capacitors $C_{1}$ and $C_{2}$. It also includes power factor, total harmonic distortion, the input power $P_{i}$, output power $P_{0}$, and the power efficiency $\eta$.

Table 3. Comparison results without capacitors variation.

\begin{tabular}{ccccccccc}
\hline Circuit & $\boldsymbol{I}_{\boldsymbol{s}}(\mathrm{A})$ & $\boldsymbol{V}_{\mathbf{1}}(\mathrm{V})$ & $\boldsymbol{V}_{\mathbf{2}} \mathbf{( V )}$ & $\mathbf{P F}$ & $\mathbf{T H D}$ & $\boldsymbol{P}_{\boldsymbol{o}}(\mathbf{W})$ & $\boldsymbol{P}_{\boldsymbol{i}}(\mathrm{W})$ & $\boldsymbol{\eta}(\mathbf{\%})$ \\
\hline \multirow{3}{*}{ CV1 } & 0.225 & 225 & 225 & 0.9926 & 0.1203 & 101.2 & 101.9 & 99.31 \\
\cline { 2 - 9 } & 0.168 & 225 & 225 & 0.9819 & 0.1623 & 75.9 & 76.4 & 99.34 \\
\cline { 2 - 9 } & 0.112 & 225 & 225 & 0.9506 & 0.2315 & 50.6 & 50.9 & 99.41 \\
\hline \multirow{3}{*}{ CV2 } & 0.225 & 225 & 225 & 0.9846 & 0.1108 & 101.3 & 101.9 & 99.41 \\
\cline { 2 - 9 } & 0.168 & 225 & 225 & 0.9778 & 0.1466 & 75.95 & 76.3 & 99.54 \\
\cline { 2 - 9 } & 0.112 & 225 & 225 & 0.9669 & 0.2111 & 50.6 & 50.8 & 99.60 \\
\hline \multirow{3}{*}{ CV3 } & 0.2249 & 224.9 & 224.9 & 0.9909 & 0.1175 & 101.2 & 101.8 & 99.41 \\
\cline { 2 - 9 } & 0.168 & 225 & 225 & 0.9758 & 0.1617 & 75.9 & 76.3 & 99.47 \\
\cline { 2 - 8 } & 0.112 & 225 & 225 & 0.9412 & 0.2298 & 50.6 & 50.8 & 99.60 \\
\hline
\end{tabular}

Table 3 shows that for a load current of $0.225 A$ and $0.168 A$, the best PF is obtained with CV1. In other cases, the best values for PF, THD and efficiency are obtained with the circuit CV2; nevertheless, the difference with circuit CV1 for the worst case was 0.0163 to PF when $I_{s}=0.168$, THD of 0.0204 with a load current of $I_{s}=0.112$. Finally, difference in power efficiency of $0.19 \%$ when $I_{S}=0.168$. Thus, circuit CV1 displays results similar to those of CV2 with a slight variation in PF, THD and power efficiency. It should be noted that the results show no variation in the condensers; therefore, the voltage is equally distributed, which is an ideal case. Thus, Table 3 shows that the values for $V_{1}$ and $V_{2}$ are the same.

Figure 16 displays the results for CV1 to observe the wave's shape at full load $I_{S}=0.225 \mathrm{~A}$. Likewise, Figure 17 shows the results for CV2 and Figure 18 for CV3, where $i_{g}$ and $v_{g}$ are the source current and voltage signals. From the results, when having converters with power factor correction, the current signal $i_{g}$ tends to be in phase with the voltage signal $v_{g}$. 


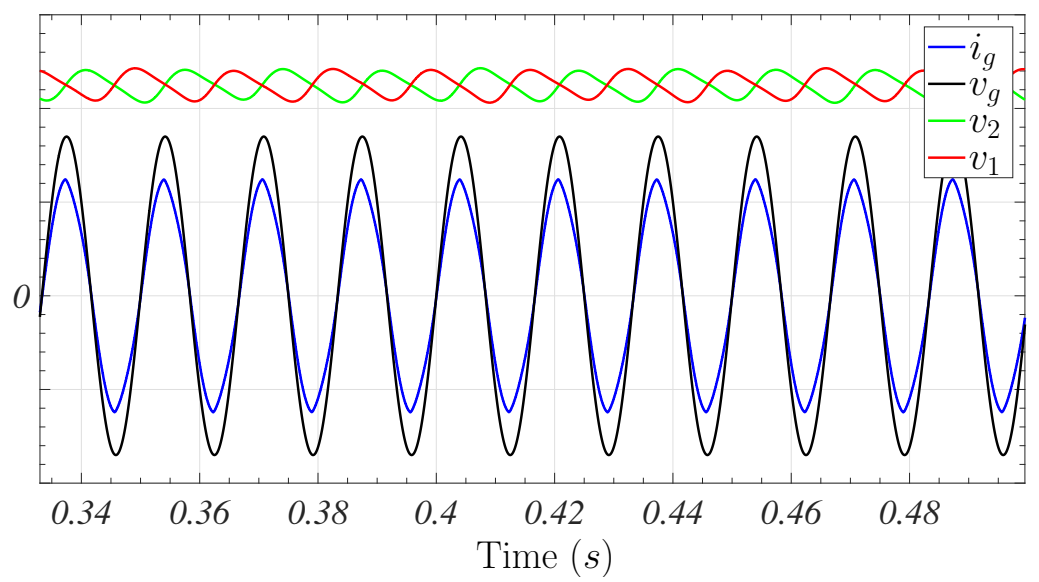

Figure 16. Waveforms obtained for CV1; $i_{g}: 1 \mathrm{~A} / \mathrm{div}, v_{g}, v_{1}$ and $v_{2}: 100 \mathrm{~V} / \mathrm{div}$.

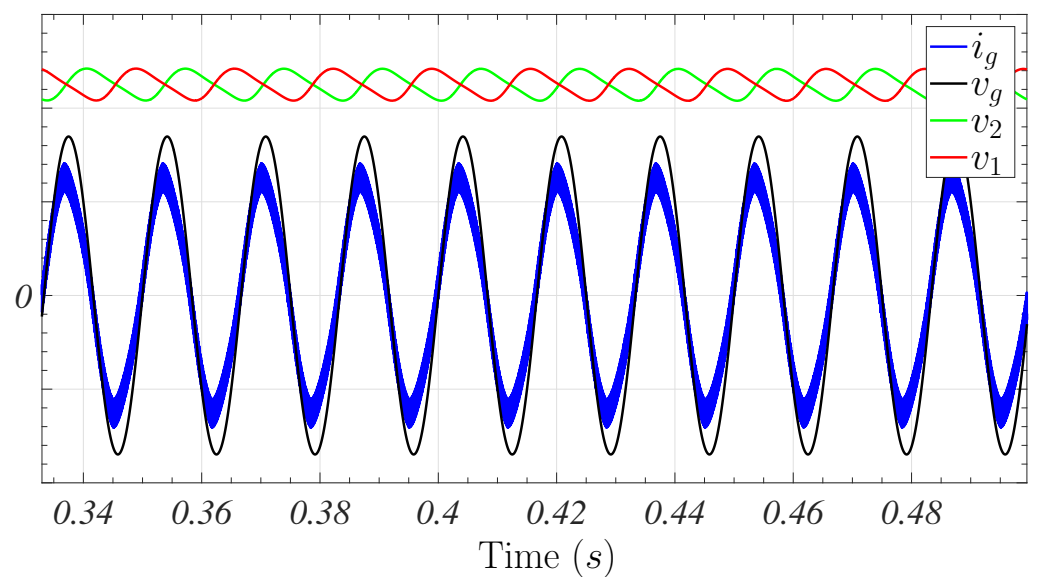

Figure 17. Waveforms obtained for CV2; $i_{g}: 1 \mathrm{~A} / \mathrm{div}, v_{g}, v_{1}$ and $v_{2}: 100 \mathrm{~V} / \mathrm{div}$.

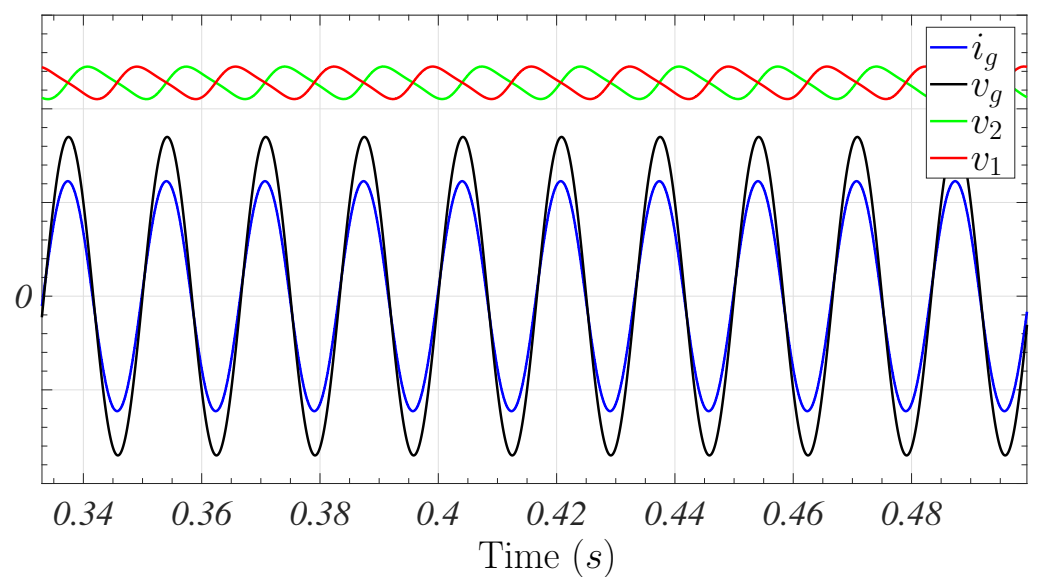

Figure 18. Waveforms obtained for CV3; $i_{g}: 1 \mathrm{~A} / \mathrm{div}, v_{g}, v_{1}$ and $v_{2}: 100 \mathrm{~V} / \mathrm{div}$.

In the previous results, the condenser's value variations are disregarded; therefore, the following experimental test focuses on observing the effect when the condensers have value variations toward $\pm 5 \%$ of the nominal value. Table 4 displays such results when considering the circuit operation at full load. 
Table 4. Comparison results with capacitors variation.

\begin{tabular}{cccccc}
\hline Circuit & $C_{\mathbf{1}}(\mu \mathrm{F})$ & $C_{\mathbf{2}}(\mu \mathrm{F})$ & $V_{\mathbf{1}}(\mathrm{V})$ & $V_{\mathbf{2}}(\mathrm{V})$ & $\mathbf{P F}$ \\
\hline \multirow{2}{*}{ CV1 } & 95 & 105 & 225 & 225 & 0.9925 \\
\cline { 2 - 6 } & 105 & 95 & 225 & 225 & 0.9925 \\
\hline \multirow{2}{*}{ CV2 } & 95 & 105 & 223.9 & 226.2 & 0.9845 \\
\cline { 2 - 6 } & 105 & 95 & 226.2 & 223.9 & 0.9845 \\
\hline \multirow{2}{*}{ CV3 } & 95 & 105 & 227.9 & 227.9 & 0.9923 \\
\cline { 2 - 6 } & 105 & 95 & 227.9 & 227.9 & 0.9923 \\
\hline
\end{tabular}

Table 4 shows that the CV1 configuration reduces the imbalance by presenting the best PF while CV2 displays the largest imbalance, also affecting PF. Moreover, circuit CV3 fulfills equality in the values $V_{1}$ and $V_{2}$; nevertheless, this is done employing a value greater than 225 , which should be the operation value. It is noticeable that $\mathrm{CV} 3$ incorporates a feedback loop to correct the imbalance.

\section{Experimental Results}

A prototype of the voltage doubler boost rectifier with the proposed equalizer circuit was built in the laboratory (Figure 19), with the circuit parameters shown in Table 5. The selection is made considering the recommendations of [5], $L$ is first calculated using the equation:

$$
L=\frac{V_{s}}{4 f_{s} \delta i_{L, p-p}}
$$

where $\delta i_{L, p-p}=0.4 \mathrm{~A}$ maximum ripple current (value desired), $f_{S}=50 \mathrm{kHz}$ switching frequency, $V_{s}=450 \mathrm{~V}$ output voltage; using these values the inductance value obtained is $L \approx 5 \mathrm{mH}$. Afterwards, the capacitors $C_{1}=C_{2}=C$ are calculated using equation:

$$
C=\frac{1}{\delta v_{s, p-p} V_{s}} \sqrt{\frac{\left(V_{p}+r_{\rho} I_{p}\right)^{2} I_{p}^{2}}{\omega^{2}}+L^{2} I_{p}^{4}}
$$

where $\delta v_{s, p-p}=10 \mathrm{~V}$ is the peak-to peak capacitors voltage variation (value desired), $V_{p}=120 \sqrt{2}$ $\mathrm{V}$ the source peak voltage, $I_{p}=0.9927$ A peak current, $\omega=2 \pi 60 \mathrm{rad} / \mathrm{s}$ line frequency, $r_{\rho} \approx 0$ loss resistance associated with components. Using these values, the capacitors $C_{1}$ and $C_{2}$ are $100 \mu \mathrm{F}$.

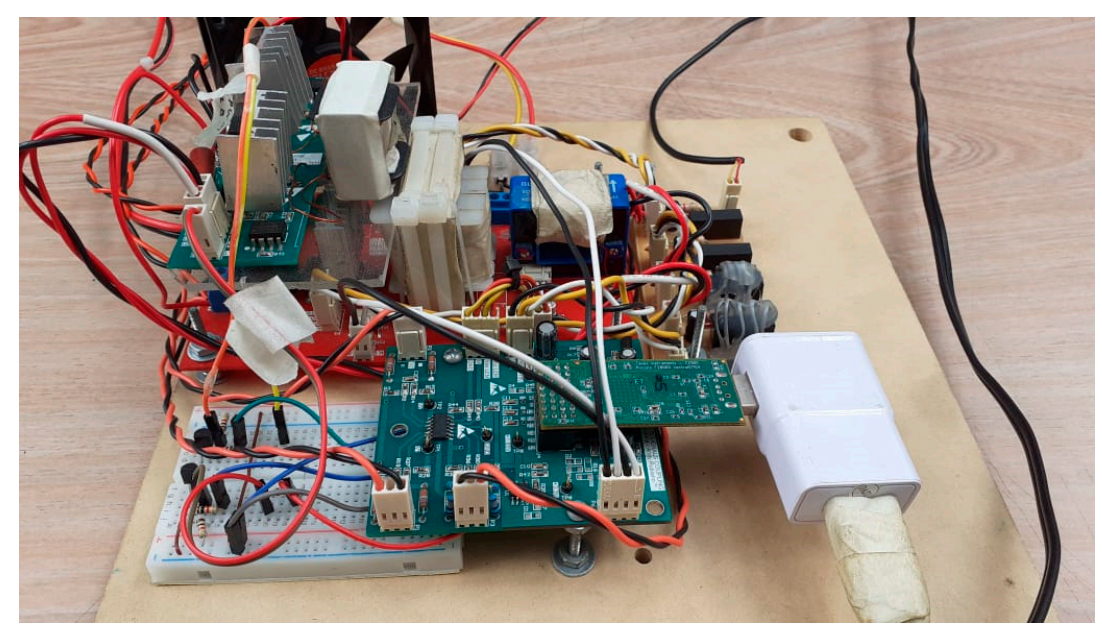

Figure 19. Prototype of the voltage doubler boost rectifier. 
Likewise, the semiconductors employed are diodes MUR460, transistors STP13NK60ZFP (ST Microelectronics), and the integrated circuited HCPL-3120 as the trigger driver. The controller was implemented with the digital signal processor (DSP) Texas Instruments TMDX28069USB (Piccolo F28069). In addition, the measurement equipment used are:

- Oscilloscope: Agilent MSO-X 3014A.

- Current probe: Keysight 1146B $100 \mathrm{kHz} / 100 \mathrm{~A}$.

- Current probe: N2783B $100 \mathrm{MHz} / 30 \mathrm{Arms}$ AC/DC.

Table 5. Parameters of the voltage doubling step-up rectifier with the proposed equalizer circuit.

\begin{tabular}{ccc}
\hline Circuit Parameter & Symbol & Value \\
\hline Peak line voltage & $V_{p}$ & $170 \mathrm{~V}$ \\
\hline Output voltage & $V_{s}$ & $450 \mathrm{~V}$ \\
\hline Equalizer inductance & $L$ & $500 \mu \mathrm{H}$ \\
\hline Rectifier inductance & $L_{g}$ & $5 \mathrm{mH}$ \\
\hline Output capacitors & $C=C_{1}=C_{2}$ & $100 \mu \mathrm{F}$ \\
\hline Load resistance & $R$ & $2 \mathrm{k} \Omega$ \\
\hline Line frequency & $f_{L}$ & $60 \mathrm{~Hz}$ \\
\hline $\begin{array}{c}\text { Switching frequency } \\
\text { rectifier and equalizer }\end{array}$ & $f_{s}$ & $50 \mathrm{kHz}$ \\
\hline Duty cycle of $S_{1}$ and $S_{2}$ & $d$ & 0.125 \\
\hline $\begin{array}{c}\text { Hysteresis band } \\
\text { of the comparator }\end{array}$ & - & $\pm 3 \mathrm{~V}$ \\
\hline
\end{tabular}

The experimental results show how the proposed equalizer circuit eliminates the voltage imbalance. Figures 20-23 illustrate the waveforms of $v_{1}, v_{2}, S_{1}$ and $S_{2}$ for values $I_{S}$ of $222 \mathrm{~mA}, 198 \mathrm{~mA}$, $153 \mathrm{~mA}$ and $110 \mathrm{~mA}$, respectively. The signals of $S_{1}$ and $S_{2}$ are measured at the output of the DSP. The operation of the proposed equalizer circuit can be verified by the absence of voltage imbalance in the output capacitors for the load current values. Moreover, by the way $S_{1}$ and $S_{2}$ work, it can be seen that when $V_{1}>V_{2}, S_{1}$ and $D_{2}$ commute so that $L$ absorbs energy from $C_{1}$ which is delivered to $C_{2}$; then, $V_{1}$ decreases at the same time $V_{2}$ increases.

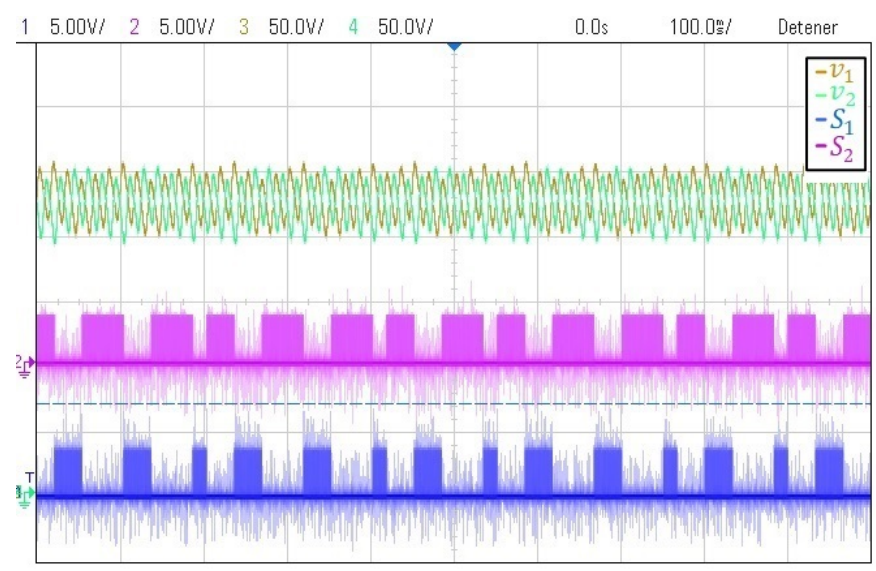

Figure 20. Waveforms of $v_{1}, v_{2}, S_{1}$ and $S_{2}$ for $I_{S}=222 \mathrm{~mA}$. 


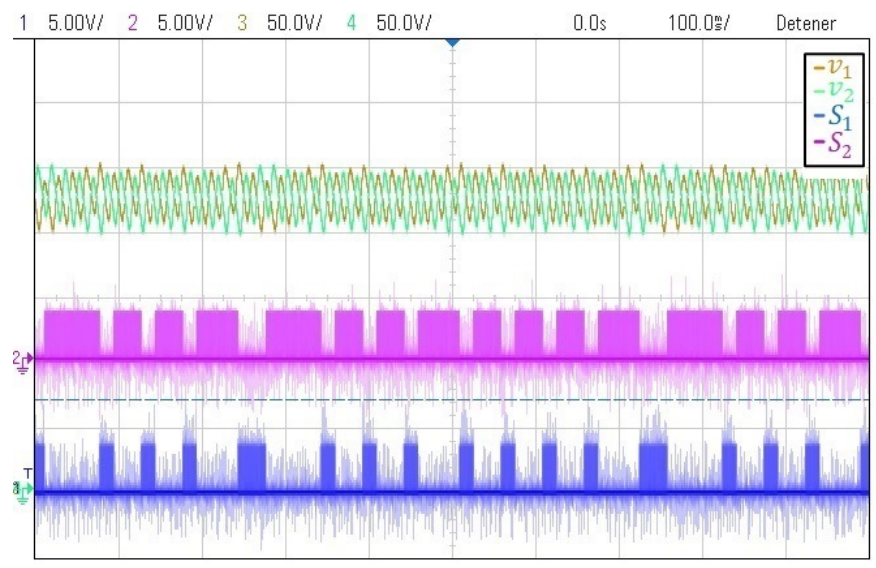

Figure 21. Waveforms of $v_{1}, v_{2}, S_{1}$ and $S_{2}$ for $I_{S}=198 \mathrm{~mA}$.

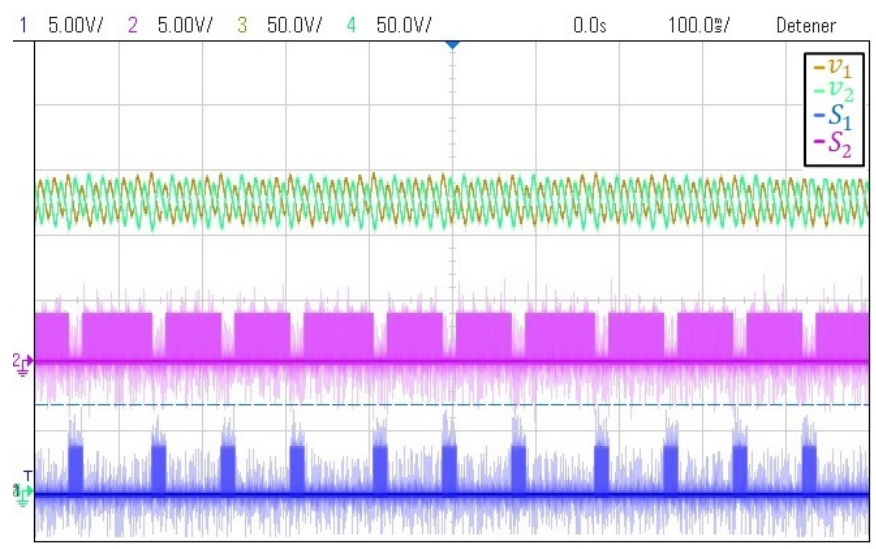

Figure 22. Waveforms of $v_{1}, v_{2}, S_{1}$ and $S_{2}$ for $I_{S}=153 \mathrm{~mA}$.

Additionally, when $V_{2}>V_{1}, S_{2}$ and $D_{1}$ commute so that $L$ absorbs energy from $C_{2}$ which is delivered to $C_{1}$; hence, $V_{2}$ decreases and simultaneously $V_{1}$ increases; consequently, that mentioned in Sections 2 and 4 is confirmed regarding the circuit operation and elimination of voltage imbalance.

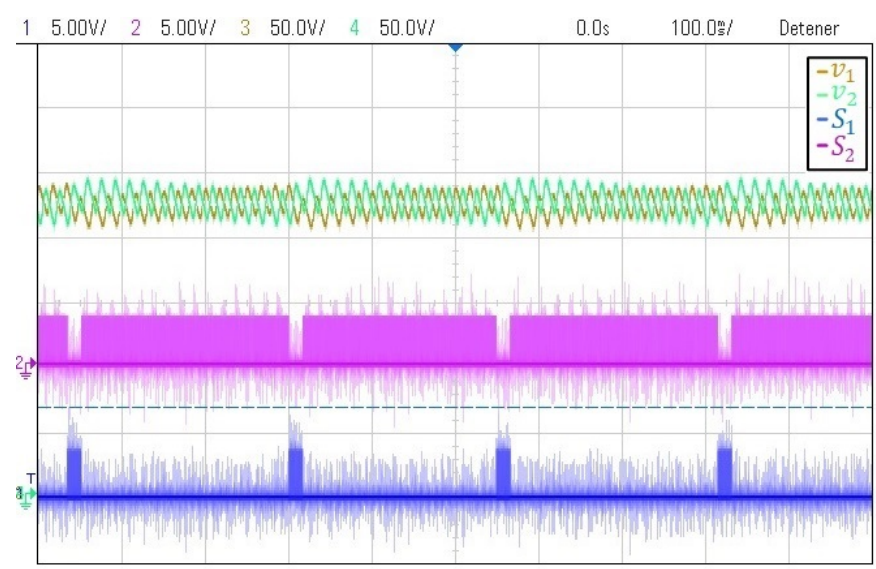

Figure 23. Waveforms of $v_{1}, v_{2}, S_{1}$ and $S_{2}$ for $I_{S}=110 \mathrm{~mA}$.

On the other hand, Figures 24 and 25 shows how the input current $i_{g}$ follows input voltage $v_{g}$, for values $I_{S}$ of $222 \mathrm{~mA}$ and $198 \mathrm{~mA}$, respectively, so that the proposed equalizing circuit does not affect the operation of the voltage doubling step-up rectifier; in addition, high power factor values were obtained under steady-state conditions, these values were 0.995 and 0.992 for values $I_{s}$ of $222 \mathrm{~mA}$ and $198 \mathrm{~mA}$. 


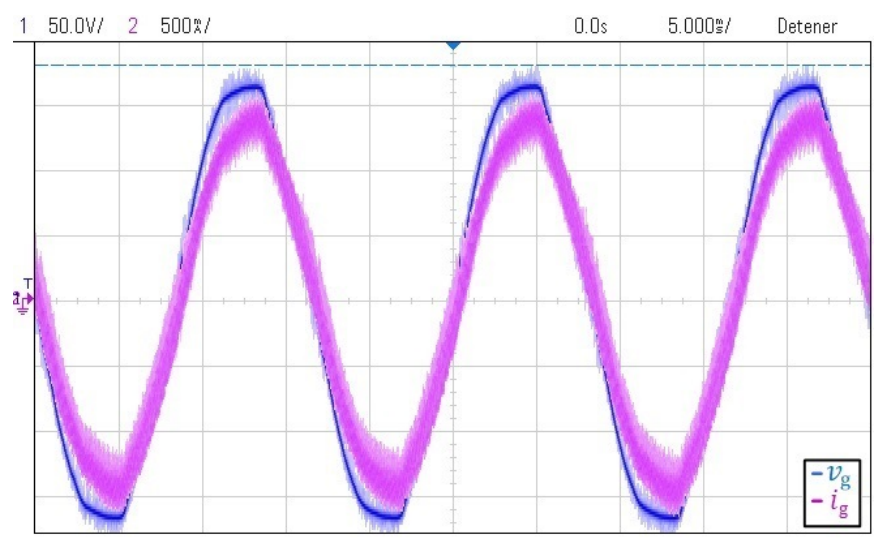

Figure 24. Waveforms of $v_{g}$ and $i_{g}$ for $I_{S}=222 \mathrm{~mA}$.

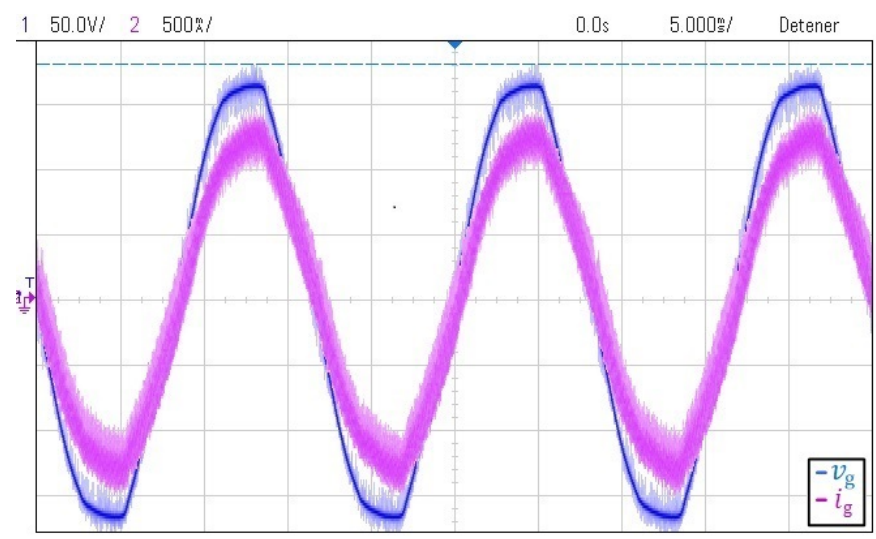

Figure 25. Waveforms of $v_{g}$ and $i_{g}$ for $I_{S}=198 \mathrm{~mA}$.

As discussion, it is observed that the proposed circuit allows reducing the imbalance in the voltage of the condensers without affecting the power factor. However, it is mandatory to employ additional components with a control system, enhancing the construction and cost complexities.

\section{Conclusions}

An equalizing converter circuit operating on DCM was proposed to solve the voltage imbalance problem. The equalizer circuit operation was described qualitatively; moreover, an average circuit model was obtained consisting of two power sources. The model was used to analyze in detail how the equalizer eliminates the voltage imbalance in the capacitors; for this, the expressions that define the average currents that flow through both capacitors were calculated, obtaining the voltage variations, as well as the variation of the voltage difference over a switching period, in each operating mode of the equalizer. In addition, a simple hysteretic band control scheme was proposed that manages the "on" and "off" of the equalizer switches.

The analysis results were verified by experiments carried out on a prototype built in the laboratory. The results show how the equalizer circuit eliminates the voltage imbalance in steady state for different load conditions; thus, a high power factor is demonstrated at full load. Therefore, the equalizer circuit does not affect the operation of the voltage doubler boost rectifier.

The comparison made concerning to other classical topologies allows appreciation that the proposed circuit does not present a decrease in the power factor when there is variation in the capacitor's value; however, it is necessary to use additional components, which increases its complexity.

In further work, it is expected another controller be developed to eliminate voltage imbalance across the converter capacitors using the model of the two power sources proposed in this paper. 
Author Contributions: Conceptualization, J.B., N.G. and H.E.; Methodology, J.B., N.G. and H.E.; Project administration, J.B.; Supervision, J.B.; Validation, J.B.; Writing—original draft, J.B. and H.E.; Writingreview \& editing, J.B., N.G. and H.E. All authors have read and agreed to the published version of the manuscript.

Funding: This research received no external funding.

Acknowledgments: The authors express gratitude to the Universidad Distrital Francisco José de Caldas, and also to the Universidad ECCI.

Conflicts of Interest: The authors declare no conflict of interest.

\section{References}

1. Shukla, A.; Pradhan, M.K. A neural network controller for high power factor in fly back converters. In Proceedings of the 2016 International Conference on Research Advances in Integrated Navigation Systems (RAINS), Bangalore, India, 6-7 May 2016.

2. Rocabert, J.; Luna, A.; Blaabjerg, F.; Rodríguez, P. Control of power converters in ac microgrids. IEEE Trans. Power Electron. 2012, 27, 4734-4749. [CrossRef]

3. Hung, C.-Y.; Wu, J.-C.; Chen, Y.-L.; Jou, H.-L. A gridconnected battery charger with power factor correction. In Proceedings of the 2016 IEEE 11th Conference on Industrial Electronics and Applications (ICIEA), Hefei, China, 5-7 June 2016.

4. Bodetto, M.; Aroudi, A.E.; Cid-Pastor, A.; Calvente, J.; Salamero, L.M. Design of ac dc pfc high-order converters with regulated output current for low-power application. IEEE Trans. Power Electron. 2016, 31, 2012-2025. [CrossRef]

5. Bayona, J.; Chamorro, H.; Sánchez, A.; Aguillón J.; Rubio, D. Linear control of a power factor correction rectifier in half-bridge configuration. In Proceedings of the IEEE CACIDI 2016-IEEE Conference on Computer Sciences, Buenos Aires, Argentina, 30 November-2 December 2016; pp. 1-6.

6. Bolívar, F.; Díaz, N.; Bayona, J. Design and implementation of a digital PID controller with pre-compensation loop for a half-bridge PFC Boost converter. Rev. UIS Ing. 2020, 19, 179-192.

7. Cho, K.S.; Lee, B.K.; Kim, J.S. CRM PFC Converter with New Valley Detection Method for Improving Power System Quality. Electronics 2020, 9, 38. [CrossRef]

8. Kang, B.-G.; Kim, C.-E.; Black, J.; Kim, D.-K.; Moon, G.-W. A high power density and power factor cascade buck-boost pfc under expanded high line voltage. In Proceedings of the IEEE Transportation Electrification Conference and Expo, Asia-Pacific (ITEC AsiaPacific), Busan, Korea, 1-4 June 2016.

9. Sheela, V.; Gopinath, M. Effiency analysis of bridgeless cuk converter for pfc applications. In Proceedings of the International Conference on Information Communication and Embedded Systems (ICICES), Chennai, India, 21-22 February 2013.

10. Xie, X.; Li, J.; Peng, K.; Zhao, C.; Lu, Q. Study on the singlestage forward-flyback pfc converter with qr control. IEEE Trans. Power Electron. 2016, 31, 430-442. [CrossRef]

11. Sun, D.; Xu, S.; Sun, W.; Lu, S. A new digital predictive control strategy for boost pfc converter. IEICE Electron. Express 2015, 12, 20150726. [CrossRef]

12. Dung, N.A.; Hieu, P.P.; Chiu, H.-J.; Hsieh, Y.-C.; Lin, J.-Y. A new digital control strategy of boost pfc at high-line light-load condition. In Proceedings of the IEEE International Conference on Industrial Technology (ICIT), Taipei, Taiwan, 14-17 March 2016.

13. Kamalapathi, K.; Priyadarshi, N.; Padmanaban, S.; Holm-Nielsen, J.B.; Azam, F.; Umayal, C.; Ramachandaramurthy, V.K. A Hybrid Moth-Flame Fuzzy Logic Controller Based Integrated Cuk Converter Fed Brushless DC Motor for Power Factor Correction. Electronics 2018, 7, 288. [CrossRef]

14. Park, J.H.; Kim, D.J.; Lee, K.B. Predictive Control Algorithm Including Conduction-Mode Detection for PFC Converter. IEEE Trans. Ind. Electron. 2016, 63, 5900-5911. [CrossRef]

15. Marcos-Pastor, A.; Vidal-Idiarte, E.; Cid-Pastor, A.; Martinez-Salamero, L. Interleaved Digital Power Factor Correction Based on the Sliding-Mode Approach. IEEE Trans. Power Electron. 2016, 31, 4641-4653. [CrossRef]

16. Fernandes, R.; Trescases, O. A Multimode 1-MHz PFC Front End With Digital Peak Current Modulation. IEEE Trans. Power Electron. 2016, 31, 5694-5708. [CrossRef]

17. Heydari, H.; Monfared, M. An Integrated Interleaved Dual-Mode Time-Sharing Inverter for Single Phase Grid Tied Applications. IEEE Trans. Ind. Electron. 2019, 66, 286-296. [CrossRef] 
18. Pourfaraj, A.; Monfared, M.; Heydari, H. Single-Phase Dual-Mode Interleaved Multilevel Inverter for PV Applications. IEEE Trans. Ind. Electron. 2020, 67, 2905-2915. [CrossRef]

19. Abbaszadeh, M.A.; Monfared, M.; Heydari, H. High-buck in Buck and High-boost in Boost Dual-Mode Inverter (Hb² DMI). IEEE Trans. Ind. Electron. 2020, doi:10.1109/TIE.2020.2988240. [CrossRef]

20. Hosseini, S.H.; Ghazi, R.; Heydari, H. An Extendable Quadratic Bidirectional DC-DC Converter for V2G and G2V Applications. IEEE Trans. Ind. Electron. 2020, doi:10.1109/TIE.2020.2992967. [CrossRef]

21. Samsudin, N.A.; Ishak, D.; Ahmad, A.B. Design and experimental evaluation of a single-stage AC/DC converter with PFC and hybrid full-bridge rectifier. Eng. Sci. Technol. Int. J. 2018, 21, 189-200. [CrossRef]

22. Cheng, C.A.; Chang, C.H.; Cheng, H.L.; Chang, E.C.; Chung, T.Y.; Chang, M.T. A Single-Stage LED Streetlight Driver with Soft-Switching and Interleaved PFC Features. Electronics 2019, 8, 911. [CrossRef]

23. Tung, N.T.; Tuyen, N.D.; Huy, N.M.; Phong, N.H.; Cuong, N.C.; Phuong, L.M. Design and Implementation of $150 \mathrm{~W}$ AC/DC LED Driver with Unity Power Factor, Low THD, and Dimming Capability. Electronics 2020, 9, 52. [CrossRef]

24. Kang, F.; Park, S.J.; Cho, S.E.; Kim, J.M. Photovoltaic power interface circuit incorporated with a buck-boost converter and a full-bridge inverter. Appl. Energy 2005, 82, 266-283. [CrossRef]

25. Srinivasan, R.; Oruganti, R. A unity power factor converter using half-bridge boost topology. IEEE Trans. Power Electron. 1998, 13, 487-500. [CrossRef]

26. Lo, Y.K.; Chiu, H.J.; Song, T.H. Elimination of voltage imbalance between the split capacitors in three-phase half-bridge switch-mode rectifiers. In Proceedings of the 4th IEEE International Conference on Power Electronics and Drive Systems, Denpasar, Indonesia, 25 October 2001.

27. Lo, Y.K.; Song, T.H.; Chiu, H.J. Analysis and elimination of voltage imbalance between the split capacitors in half-bridge boost rectifiers. IEEE Trans. Ind. Electron. 2002, 49, 1175-1177.

28. Lo, Y.K.; Ho, C.T.; Wang, J.M. Elimination of the Output Voltage Imbalance in a Half-Bridge Boost Rectifier. IEEE Trans. Power Electron. 2007, 22, 1352-1360. [CrossRef]

29. Erickson, R.W.; Maksimovic, D. Fundamentals of Power Electronics; Springer: Berlin/Heidelberg, Germany, 2001.

30. Bayona, J.; Guarnizo, J.; Gelvez, N. Pulse Width Prediction Control Technique Applied to a Half-Bridge Boost. Tecciencia 2018, 13, 48-54.

Publisher's Note: MDPI stays neutral with regard to jurisdictional claims in published maps and institutional affiliations.

(C) 2020 by the authors. Licensee MDPI, Basel, Switzerland. This article is an open access article distributed under the terms and conditions of the Creative Commons Attribution (CC BY) license (http://creativecommons.org/licenses/by/4.0/). 